\title{
A Review of PIP Supervision: Compari- son between China and the Developed Countries to Build a Management Supervision Mode
}

\author{
Yunna Wu Haozhen Qi Yifan Feng Narenmandula Heping Wang \\ School of Economics and Management North China Electric Power University \\ Beijing China
}

\begin{abstract}
The public investment project (PIP) plays an important role in national economy in China. According to the comparison between China and the developed countries in the fields of law foundation, regulatory bodies, supervision methods and the key supervision stages, we find shortcomings in PIP supervision system. Make detailed suggestions to the key supervision phases of decision-making, construction, postevaluation, and especially credit and accountability mechanism. It creates a new mode for supervision, illustrates decision procedures, relationship constraints, and puts forward a construction management supervision framework with five targetsoriented.
\end{abstract}

Keywords: public investment project (PIP); agent construction system (ACS); supervision mode; decision-making; law and policy

\section{Introduction}

After the implementation of reform and opening up policy, with China's economic system reform deepening, the investor diversification structure appears and the definition of public investment project gradually forms whose funds come from financial funds, financial guaranty bank loans and international aid funds. Public investment project is an important part of the total investment in fixed assets in the whole country, a method that government fulfills its functions and plays a significant role in China's economic development, social and cultural life.

In China, according to the characteristics of the construction projects, the PIP can be divided into profit and non-profit types which pursuit to maximize the society benefits. PIP are mostly concentrated on the public projects that serve for the social development, such as governmental buildings, national defense projects, social undertakings in the field of science, education, culture, health and sports, municipal facilities and utilities.

\section{The Comparison and analysis be- tween China and the developed countries}

\subsection{The regulatory law system founda- tion}

From the view of supervision of PIP in the developed countries, the perfect law system is the foundation and protection. The strict supervision methods in the developed countries include: establish regulatory bodies with clear responsibilities and rights, set down stringently transparent process, create regulatory system combined the internal and external. 
Nowadays, many laws have related contents about major projects supervision from different aspects, such as bidding law, National key construction project management approach, State supervision of major construction projects bidding Interim Measures, Report violations of major construction projects (Trial), Construction Quality Control Regulations, Inspection of major national construction projects means, etc.

These laws involve in the supervision of major government investment projects, however they are all relatively isolated and there is still no law that is only for the monitoring. They have a few questions as below:

(1)Department or local laws and regulations may be inconsistent with the national laws for the benefit of their own.

(2)Some provisions are empty and cannot guide the concrete operations.

(3)The responsibilities and rights of the regulatory bodies are unclear which causes the supervision leaks easily.

(4)The punishment of violations is not enough that it cannot warn the violators well.

\subsection{The regulatory bodies}

The developed countries generally found specialized agencies to be in charge of the construction and management of PIP: (1) in America, for the general PIP, the government implements specialized management by different departments, and special management for the lager projects. (2) in UK, the decision-making of PIP is guided by public service delivery agency directly under the Prime Minister's Office and after the project is set up, project authorities organize to bid with Office of Government Commerce and its subordinate bodies. (3)in Germany, Federal Ministry of Transport, Building and Housing Department takes charge of the mostly PIP construction and management on be- half of State Construction Administrative Department.

In China, it is the responsibility of the Major Projects Inspection Office under the Development and Reform Commission to monitor the major projects. In addition, the audit department, the financial department and the supervision ministry also have some related duties.

\subsection{The regulatory methods}

The supervision in the developed counties is dynamic and overall process.

Dynamic supervision means that during the PIP, the government sends the supervisors or review engineers to examine randomly and once they find problems, they will order to correct directly. In general, the number of the projects that one supervisor or one review engineer is not over five.

Overall process supervision means that the government implements strict regulation from the decision-making phase to the final acceptance of construction phase. It is used in the ADB and World Bank Loan Projects that their monitoring evaluation mainly depends on the evaluation during the project preparation stage, the supervision during the construction phase and the post-evaluation after the project is finished.

\subsection{The supervision of the key stages}

From the study of the developed countries, we can see there are five key stages to supervise the PIP: one is to regulate the formulation of the plan and the government personnel decision-making deeds in the decision-making stage; one is for the budget drafting and approval procedures in the budget management phase; one is for the construction participators in the construction stage; one is risk management; one is looking into the offenders. In the five stages, China mainly puts their energy in the construction phase, and ignores the other four ones. 


\section{The new design of the PIP each stage supervision mode}

\subsection{Decision-making stage supervision}

(1)The design of the PIP decision-making process: Currently, the decision-making process in China consists of assessment and demonstration of the project proposals, feasibility study report, preliminary design, the total budget, the annual PIP plan and construction design, the examination and endorse of the project budget and the evaluation of the project pre-tender.

The design of the decision-making process is from the macro aspect which means the decision-making process of the project plan and micro aspect which means specific PIP examination and approval process. The decision-making process of the PIP is as follow:

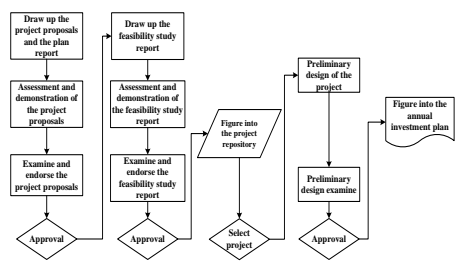

Figure 1: The PIP decision-making process

(2)The establishment of the PIP decision-making restricted relationship: In the decision-making process, the government department should assess and prove the project in virtue of the social forces, for example consulting company, technical panel and so on and the report gotten should be announce to the public and accept the masses supervision. Besides, we can establish the independent specialized regulatory bodies according to the developed countries experience.

(3)The improvement of the PIP decision-making regulatory system: In the decision-making stage, China PIP should improve the following institutions.
(1) PIP reserve institution. (2) PIP experts advisory institution.

\subsection{The supervision of the PIP con- struction stage}

(1)Regulatory concept of contract management as the core: Contract management is the core to archive the agentconstruction management targets such as the duration, quality, investment, quality and so on. The risk during the construction process can be controlled through the strict control methods of the contract management system.

(2)The project targets-oriented regulatory pattern: The PIP need to build the project target-oriented regulation model that can start from five targets --the process, quality, cost, environment and safety among which the process, quality and cost targets are the core of the project management and the traditional three targets.

(3)Information system to support regulatory measure: In the front of the paper, we put forward the whole process and comprehensive regulation way that come true via the advanced information technology and modern information systems.

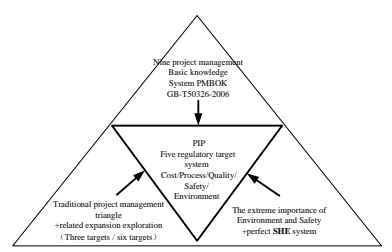

Figure 2: Five regulatory targets system proposed path

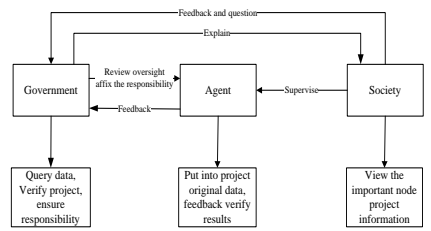

Figure3: The framework of real-time monitoring information platform 


\subsection{Credit and accountability mecha- nisms}

We assume to implement the kind of regulatory process: some particular government departments evaluate the management works in the regulatory points that are choose during the whole process of the PIP, feedback the regulatory results and related advises to the agent and monitor the agents to correct.

During the regulatory process, we can establish the agents' credibility record. On one hand, according to the evaluation situation, we can get an original credit, on the other hand, according to the response to the evaluation and advises, we can get a modified credit. The agent's credit is related to the original and modified credit.

\section{Conclusion and next steps}

Based on the comparison between China and the developed countries and the analysis of the China PIP supervision mode, there will be more things to do to improve the new design in the paper. Currently, the China PIP regulatory pattern research is still in the theoretical stage and we haven't evaluated the new measurement to make sure whether it still exists leaks. There are a lot of things to discuss in connection with the information platform including the operation process and particular technology. It is the same with the credit and accountability mechanisms. Therefore, the next steps are involved in the achievement and the details. We should put it into practice to find whether it has some advantages or leaks and improve further.

\section{Acknowledgements}

The authors would like to acknowledge the supports by Chinese National Nature Science Foundation of China (No.71271085) and Beijing Twelfth Five
Year Plan Project of philosophy and social sciences (No.12JGB044).

\section{References}

[1] Yunna Wu, Dongxiao Niu. Theory and Practice of Agent Construction System of Government Investment Projects. Beijing: Electronics Industry Press, China, (2007).

[2] Ling Yan, Linggang Yang and Hua Zhao. 'Research frame for incentive mechanism of the construction agent in government investment project: from the perspective of project governance.' 2009 IEEE International Conference on Industrial Engineering and Engineering Management (IEEM 2009), pp1513-1517.

[3] Chuntian Jin, Kan Lv. The government investment supervision experience and inspiration of the market economies countries. China Economic \& Trade Herald,17,(2006).

[4] Zengyi Xie. Germany's economic stability and growth promotion law and the new revelation. Contemporary Law, 3(2002), pp 133-137.

[5] Sees Elizabeth, Cui Qingbin and Johnson Philip. Legal Enviroment for Warranty Contracting. Journal of management in engineering, 25:3 (2009), pp115-121.

[6] Marenjak Sasa, Kusljic Danijel. Legal framework of public-private partnerships. Gradevinar, 61:2 (2009), pp137-145.

[7] Ektewan Manowong, Stephen O. Ogunlana. Public hearings in Thailand's infrastructure projects:effective participations? .Engineering,Construc tions? .Engineering,Construction and Architectural Management, 13:4(2006), pp343-363.

[8] Xi-zhen Gao, The study on decisionmaking criterion of public projects, Industrial Engineering and Engineering Management, (2010), pp 157-160. 